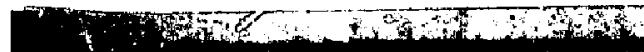

$\therefore x+a_{a}$

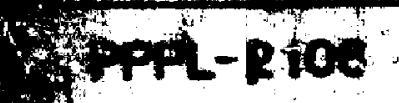

$4 x+0,4, D$

(1)

PPPL--2106

DE84 013100

ABCENT RESULTS FROA TFTR

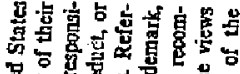

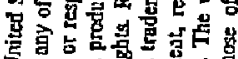

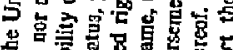

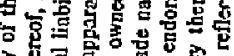

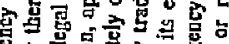

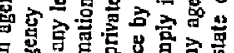

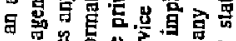

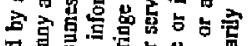

By

0

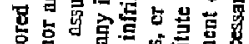

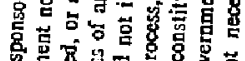

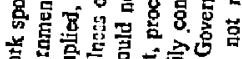

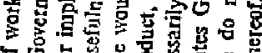

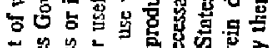

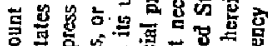

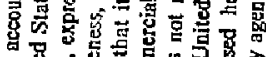

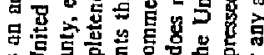

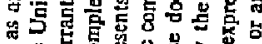

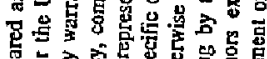

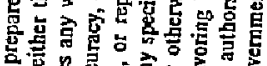

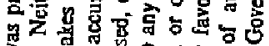

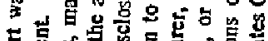

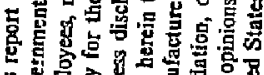

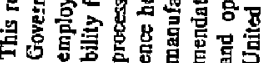

MÁY 1984

R.J. Hewryluk et al.

\title{
MSTER
}
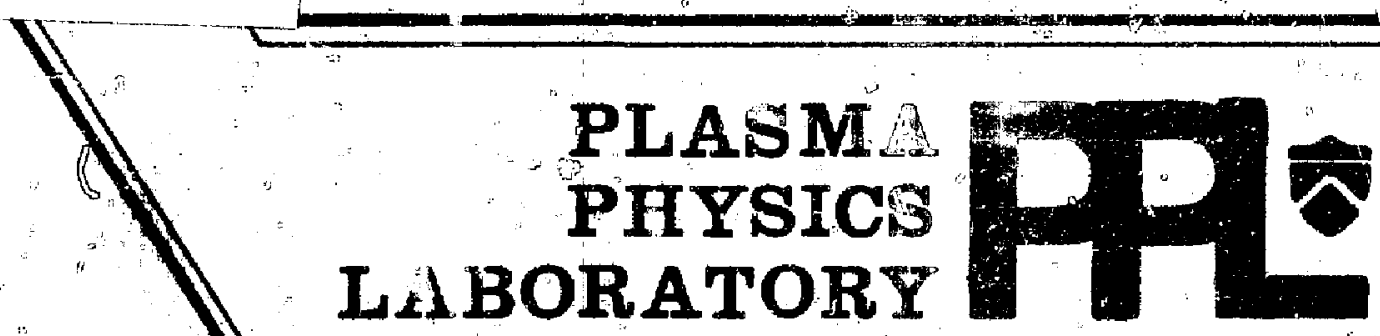

PR NCETON UNIVERSITY PRINCETON, NEW JERSEY

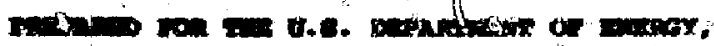

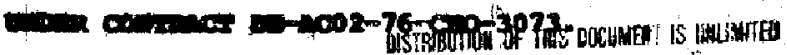




\section{RECENT RESULTS FROM TFTR}

'R. J. Hawryluk, M. G. Beil, M. Bftter, H. R. Blanchard, N. Bretz, C. Bush ${ }^{\mathrm{a}}$, J. L. Cecchi, S. Cohen, J. Coonrod, S. L. Davis,

D. Dimock, H. F. Dylla, P. C. Efthimion, R. Fonck, R. J. Goldston, S. von Goeler, B. Glek, D. J. Grove, H. Hendelb, K. W. Hill, R. Hulse, J. Isaacson, D. Johnson, L. C. Johnson, R. Kaita, S. M. Kaye, S. Kilpatrick, J. Kiraly, R. Knize, R. Little, M. McCarthy. D. Manos, D. C. McCune, K. McGuire, D. M. Meade, S. S. Medley, D. Mikkelsen, D. Muel ler, M. Murakami ${ }^{2}, E$. Nieschmidt ${ }^{C}$, D. K. Owens, A. Ransey, A. L. Roquenore, P. Stangeby, N. Sauthoff, J. Schivell, S. Scotta, S. Sesnic, J. Sinnis, J. Strachan, G. D. Tait, G. Taylor, F. Tenney, C. E. Thonas, J. Tiaberlake, H. H. Towner, M. Ulrickson, and K. M. Young

Plasma Physics Laboratory, Princeton Iniversity P.0. Box 451, Princetan, New Jersey 08544 USA

\section{ABSTRACT}

During the past year, the research activities on TFTR have encompassed three broad areas. The first was to extend the aperating range of TFTR. Plasma currents up to $1.5 \mathrm{MA}$ were achleved in discharges with a $=0.83 \mathrm{~m}$, $R=2.55 \mathrm{~m}$ at a toroidal ffeld of $2.7 \mathrm{~T}$. In these large plasmas, the maximum line average density was $3.35 \times 10^{19} \mathrm{~m}^{-3}$. The second activity was a study of the scaling of the energy confinement time; $\tau_{E}$, in ohmicaliy heated discharges as a function of plasma current, density, and plasma size. These experiments indicate a favorable scaling of ${ }^{2} E$ with size and density. Energy confinement times in excess of $0.25 \mathrm{~s}$ were obtatned in deuteriun dtscharges. The third activity was a study of adlabatic compression. During compression, the plasma current and ion temperature scaled approximately as predicted; however, the electron temperature and de.isity scaled less strongly than predicted for ideal compression. 


\section{INTRODUCTION}

The research objectives of TFTA are (1) to achleve reactor relevant temperatures $(\sim 10 \mathrm{keV})$ and densfties $\left(-10^{20} \mathrm{~m}^{-3}\right.$ ) and ( $\left.1 \mathrm{i}\right)$ to achieve approximate energy break-even between the powe- Input to and the fuston output from the plasma $(Q \sim 1)$. These objectives wt11 be achleved through the addition of neatral beam heating ( 27 MH total power of deuterium with a full energy of $120 \mathrm{keV}$ for $\sim 0.5 \mathrm{sec}$ ) anc the latter one will require tritium target plasmas. Ouring the design phase of TFTR, two different modes of operation rere envisioned to attain these obfectives: by heating large plasmas ( $a=0.85 \mathrm{~m}$ and $R=2.5 \mathrm{~m}$ ), or by heating small plasmas (a $=0.55 \mathrm{~m}$ and $A=3.05 \mathrm{~m}$ ) followed by adlabattc compression heating to $R=2.08 \mathrm{~m}$. In practice, the machine is capable of these two modes of operation and Intermediate modes as well such as partially compressing and allowing the plasma to expand freely or low-q operation at full current in a higher toroidal fleld region. Thus in order to optimize the performance of TFTR, understanding the scaling of plasma confinement with size and the effect of adfabatte compression is very important.

The activities for the past year encompassed three broad areas. The first was to extend the operating range of TFTR beyond the pararoters described by Young et ai. /1/. This Involved commissioning the machine to successively higher levels of performance and installing tinternal vacuum vessel components and additional diagnostics. The second major activity was a study of the scaling of the energy confinement time, $\tau_{E}$, in ohmically heated discharges as a function of electron density, current, and size. The third major activity was a study of adtabatic compression. These studfes were aimed at documenting confirement scaling of the target plasma for neutral beam heating experiments, which will comence in August, :984.

In previous reports, Young et al. $/ 1 /$, described the initial operation of TFTR from December 1982 through June 1983 and Efthimion et al. $/ 2 /$ describad the results of the fnitial chmic confinement time measurements. Following those experiments, an extensive fnstallation period took place. High power plasna operation resumed in November 1983 and continued into January 1984, followed by another installation period for neutral beam hardware. This paper will focus on the machine status and the results from the recent experimental run (Nov. '83-Jan. ' 84 ). Further detafled analysis of the data from the 
recent run is in progress and will be published later.

\section{MACHinE STATUS}

The installation period durfing the summer of 1983 concentrated on new Internal vacuun vessel components, additional power supply capability, and new diagnostics.

Three major internal vacuum vessel components, the moveable 1 imiter assembly, the prototype ZrAl alloy bulk getter surface pumping system, and bellows cover plates ware installed during this period. The moveable limiter assembly is composed of three water-cooled Inconel blades covered with graphite tiles. It can accommodate a wide range of plasma major and minor radif, including a range of $a=0.3$ to $0.83 \mathrm{~m}$ at a fixed major radius. Before installation, the graphtte tiles had a chentcally vapor-depostted $T+C$ coating of nominally 20 lin thickness. After the run period, examination of the initer assenbly revealed ifttie danage to the graphite tfles; however, the TiC coating was severely damaged. In addition, as will be described below, significant concentrations of titantum were observed in low density discharges. Consequently, the TiC coating wtil be chentcally renoved for future runs.

The prototype ZrAl alloy bulk getter system consists of eight arrays of ZrAl modules. The complete system, whtch will be installed in 1985, will Include 36 such arrays. In the experiments discussed below, efther six or four panels were activated. The measured deuterium pumping speed of stx panels was $1.1 \times 10^{2} \mathrm{~m}^{3} / \mathrm{s}$, which greatly exceeds the $10 \mathrm{~m}^{3} / \mathrm{s}$ pumping speed of the turhamolecular pumps. The base pressure of the vessel with the panels activated was $\sim 3 \times 10^{-7} \mathrm{pa}$. Although controlled experiments were not conducted, it appeared that the surface pumping system shortened the recovery time from a major disruption. During the june ' 83 experiments, the recovery time from a major disruption was as long as $1 / 2$ hour beyond the typical shot repetition cycle of 10 minutes. With the getters activated and using the new moveable limiter in the recent experiments, the recovery tfme from a disruption was typically no longer than the normal repetition time, even though both the plasma current and pulse duration were significantly increased. The $2 \mathrm{rAl}$ arrays are located approximately one meter toraidaliy from the moveable Ifmiter, whtch is the main source of particle recycling. As 
a result, the getters dfd not influence the recycling significantly. In general, the gas fueling requirements have been remarkably low. Typicaliy, during the density rise the gas influx was $<2.6 \mathrm{~Pa} \mathrm{~m} / \mathrm{s}$ and during the density flattop $<0.7 \mathrm{~Pa} \mathrm{~m} / \mathrm{s}$ at low currents $(<0.7 \mathrm{MA}$ ) with no gas feed at high current ( $>0.8 \mathrm{MA}$ ). For the next run perfad, neutralizer plates will be installed on the surface pumping panels in order to increase the recycling in their vicinity.

The bellows cover plates protect the vacutu vessel bellows from direct plasma bonbardment and also provide a 20 segment tnner 13 miter extending \pm 60 degrees polotdaliy from the midplane. These piates are composed of Inconel rails on which are nounted slats that are Inconel near the midplane and stainless steel elsewhere. The bellows cover alates successfully protected the tellows but showed some damage, probably due to runaway electrons and possibly due to disruptions.

The comissioning" of additional polotdal and toroldat fleld power supplies enabled us to increase the machine parameters from those reported by Young et al.11. In particular, the conntsstoning of the ohmic heating interrupters increased the volt-second capabtifty to 11 Vs and hence the plasma current to $1.5 \mathrm{MA}$, and additional toroidal field rectifiers increased the pulse duration to $\sim 4$ sec. With the avaliability of the second MG set later this year, operation of coils and power supplies at levels approaching the destgn parameters will take place.

The principal new diagnostics for the recent series of experiments are an $x$-ray crystal spectrometer to measure the central ion temperature, an x-ray imaging system to measure MHD OSC 11 tations, a multi-polnt Thomson scattering system to measure the electron temperature and density profiles, Langmutrcalorimeter probes to measure the edge plasma, a visible spectrometer, a laser impurity injector for impurity transport studies, and a neutron fluctuation detector to measure the fast variation of neutron flux.

A. Discharge cleaning

In addition to the commissioning of new hardware, the increase in operating range of TFTR has been alded by combining modest temperature bakeout $\left(120^{\circ} \mathrm{C}\right)$ with discharge cleaning $/ 3-4 /$. Pulsed discharge cieaning was the main technique for conditioning the vacuum vessel walls and limiters. Onty $\sim 20$ 
hours of glow discharge cleaning were used. Pulsed discharge cleaning is accompitished by discharging the compression capacitor banks into the ohmic heating winding to produce a 50-100 kA plasma every, 5 to 9 seconds. Approximately 25,000 hydrogen discharges were used to condition the machine with the vessel at $120^{\circ} \mathrm{C}$. During the conditionting in october, the partial pressuras of $\mathrm{H}_{2} \mathrm{O}$ and $\mathrm{CO}$ decreased from $1.4 \times 10^{-3} \mathrm{~Pa}$ to $8 \times 10^{-5} \mathrm{~Pa}$ and from $5 \times 10^{-4} \mathrm{~Pa}$ to $5 \times 10^{-5} \mathrm{~Pa}$, respectively. The partial pressures of $\mathrm{H}_{2} \mathrm{O}$ and $\mathrm{CO}$ during discharge cleaning decreased by approximately another factor of four when the vessal temperature was reduced from $120^{\circ}$ to $56^{\circ} \mathrm{C}$. After discharge cleaning in October, there was no further condftioning until early January. During this second round of canditioning, consisting of $~ 7000$ shots conducted with deuterium at a wall temperature of $\sim 80^{\circ} \mathrm{C}$, the partial pressures of $D_{2} 0$ and $c 0$ produced by discharge cleaning were quite low, $-4 \times 10^{-6} \mathrm{~Pa}$ for both gases. This second round of cleaning seened to have had little effect on $Z_{\text {eff }}$.

B. Plasma control

The plasma position, current, and density control systems described by Young et al. /1/ were used to change plasma parameters, control the discharge during compression, and maintain reproductble condftions. Figure 1 shows the evolution of plasma current, surface voltage, major radius, and line density durting a large plasma dtscharge $\left(a=0.83 \mathrm{~m}, \mathrm{~B}_{\mathrm{T}}=2.7 \mathrm{~T}\right.$ ). The applied breakdown voltage ranged from 30 to $100 \mathrm{~V} / \mathrm{turn}$. By varying the precharge current in the $O H$ transformer, It is possible to vary the flux swing, which determines the inftial plasma current level during the first $100 \mathrm{~ms}$ of the discharge. Currents as high as $770 \mathrm{kA}$ have been establtshed in $100 \mathrm{~ms}$ in plasmas at $R=2.55 \mathrm{~m}, \mathrm{a}=0.83 \mathrm{~m}$, and $\mathrm{B}_{\mathrm{T}}=2.7 \mathrm{~T}(\mathrm{q}=4.8$ ). After the initiall raptd increase, the current is raised under feedback control to a programmed level and then decreased at the end of the discharge, also under feedback control. During the current fiattop phasa, the loop voltage decays to an equilibrium value, typically $\sim 0.7 \mathrm{~V}$ at low $(0.6 \mathrm{MA})$ currents and up to $\sim 1.2 v$ at high (1.4 MA) currents, on a time scale of 0.4 to 1 sec.

The plasma posttion is measured lising a set of $B_{\theta} / B_{p}$ coils outside the vacuum vessel. These colls are used to provide both a real-time signal for the closed-loop position control system and data which are analyzed between 
shots. Independent measurements of the plasma location using electron cyclotron emission and $x$-ray imaging measurements of the location of the $q=1$ surface have shown that errors in the real-time magnetics measurements occur especially in low current, small minor radius discharges (a - 0.4-0.55 m). Part of the error arises from stray vertical fields assoctated with the toroidal field system. The deviation in the deduced plasma position from $2.55 \mathrm{~m}$ seen in Fig. 1 is due matnly to the inclusion of the stray fields in the off-ifne analysts. In addition to these quasf-static effects, which have been taken into account in all of the data in this paper, the real-time $B_{\theta} / B_{B}$ system does not yet compensate for stray flelds fnduced by plasma motion during compression experiments. Ints will be discussed further in conjunction with the compression experiments.

\section{Operating range}

Compared with the experfments in June, the present operating range of TFTR is considerably greater. Stgnificantly higher densfttes, $\vec{n}_{e}<3.35 x$ $10^{19} \mathrm{~m}^{-3}$, larger values of the Murakant $/ 5 /$ parameter $\left(\pi_{e^{R} / B_{T}}<3.1 \times 10^{19}\right.$ $\left.\pi^{-2} / T\right)$, and higher currents $\left(I_{p}<1.5 \mathrm{MA}\right)$ corresponding to a limiter $q$ of 2.5 have been achieved in the large plasmas (a $=0.83 \mathrm{~m}$ ). In plasmas with a sinaller minor radius $(a=0.69 \mathrm{~m})$ somewhat higher denstites, $\bar{n}_{\mathrm{e}}=3.62 \times 10^{19}$ $\mathrm{m}^{-3}$, were achfeved corresponding to a Murakami parameter of $3.4 \times 10^{19} \mathrm{~m}^{-2} / \mathrm{T}$. In post-compressed plasmas at $R=2.13 \mathrm{~m}$ and $\mathrm{B}_{\mathrm{T}}=3.29 \mathrm{~T}$, the nighest steadystate density was $4.2 \times 10^{19} \mathrm{~m}^{-3}$.

\section{CONFINEMENT TIME SCALING IN OHMICALLY HEATED OISCHARGES}

The dependence of the energy confinement time on-plasma current, denstity, and minor radius was extensively examined and the scaling with toroidal field was briefly studted during the recent experiments. The density and current scaling experiments were conducted in the large plasma discharges $(R=2.55 \mathrm{~m}$ and $a=0.83 \mathrm{~m}$ ). In these experiments, the plasma current was varied from 0.6 to 1.4 MA, and a density scan was taken at each condition. In the minor radius scaling experiments, the limiter $q$ was maintained in the range 2.7 to 3.5 wth nearly constant major radius and toroidal field. In these scaling experiments, the minor radius varied from 0.41 to $0.83 \mathrm{~m}$. In all the scalting 
studies, the moveable 1 fntiter was used and deutertum was the working gas. In addition, sawtooth oscillations were observed on all of the discharges in the scaling studies.

In these experiments, ordinary-mode fundamental electron cyciotron emission (ECE) measurements made with a scanning heterodjne recelver provided the electron temperature profiles. The recefver was absolutely callbrated with an uncertainty of $\pm 10 \%$. Central temperature values from the electron cyclotron. entssion measurements were conststent with a pulse helght analysis (PHA) of the $x$-ray spectrum using a single line chord. Code stmulations of the $x$-ray spectrum haye shown that the central electron temperature is approximately $10 \%$ higher than that deduced from itnear fits to the lineintegrated spectrum. The two techniques agreed to within $\pm 10 \%$ when the chord measurements were corrected for proftle effects, as shown in Fig. 2. On a linited number of shots, Thomson scattering measurements of the electron temperature proffle were obtained and analyzed. The Thomson scattering system measures the electron temperature and density proffles in one shot.

Three methods were used to measure the central fon temperature: neutron emfsion measurements during deuterium discharges, Doppler broadening measurements of the TiXXI $K_{a}$ itne, and passive charge exchange measurements. The neutron entssion measurements requite a knowledge of the deuterlum density profile. Visible spectroscopic measurements of the $D_{\alpha}$ to $H_{\alpha}$ line intensity ratio indicate that the global ratio $0:$ : 4 varted from $3: 1$ to 12 : 1 depending upon the machine history and plasma density. The density proffle is assumed to be parabolic, based on previous measurements of $n_{e} \sqrt{2}$ eff as a function of minor radtus using the visfble brensstrahlung emission and limited Thomson scattering data. The uncertainty in the central fon temperature deduced from neutron emission is estimated at $\pm 8 \%$. Though oniy chord measurements of the TixXI $K_{a}$ line emission were taken, the observed $K_{\alpha}$ line emission is emitted predominantly from the central region of the plasma. because the excltation rate coefficient decreases strongly with decreasing electron temperature. Broadening of the resonance iine due to unresolved dielectronic satellites is negligible when the electron temperature exceeds $1.3 \mathrm{keV}$. A comparison of these two fon temperature measurements is shown in Fig. 2. The passive charge exchange measurements require only small corrections ( $\leq 15 \%)$ for neutral opactity, provided $n^{2} \leq 3 \times 10^{19} \mathrm{~m}^{-2}$. In this low line-integral density range, they are in good agreement with the other 
techniques. At higher denstties, the fon temperature is more severely underestimated by uneorrected passive charge exchange measurements and the discrepancy increases sharply reaching $\sim 50 \%$ at $n_{\mathrm{e}} \sim 5 \times 10^{19} \mathrm{~m}^{-2}$, as $1 \mathrm{r}$, the case for the discharge shown in Fig. ?. After correction, the passive charge exchange fon temperature is in agreement wth the neutron in temperature during the density and current flattog to within $10 \%$.

The energy confinement time was calculated by means of both the timedependent TRANSP code, which has been described previously $16 \%$, and a new time-independent equilibrium snapshot radial proftle analysis code (SNAP). The total energy confinement time is defined by

$$
\tau_{E}=\frac{\left(W_{e}+W_{i}\right)}{P_{O H}-d / d \tau\left(H_{e}+W_{i}\right)} \text {. }
$$

where $H_{e}$ and $H_{f}$ are the electron and Ion stored energies and $P_{0 H}$ is the ohmic power dissipated in the plasma. Both codes use the plasma current, surface voltage, line density, plasma major and minor radii, and electron cyciotron emission measurements of the electron temperature profile to calculate the input power and the electron stored energy. The density profile is assumed to be parabolfc. Vartations in the density profile shape affect the energy confinernent time weakly ( $<10 \%$ ) when constrained by the measured linesintegral density. The ton temperature proffle is calculated from the ion energy balance assuming that the transfer of power from electrons to fons is through coulomb collistons. The fon heat conductivity is given by $\kappa_{j}=a k_{j}$ NC (where ${ }{ }^{N C}$ can be chosen from a number of neoclasstcal calculations) and a is adjusted to obtafn agreenent with the central ton temperature measurement. The data presented in the scaiting studies have been analyzed primarily by the equitibrium SNAP code, and the SiNAP results agree to within $5 \%$ with those from TRANSP since the discharges considered are all in steady state.

\section{A. Confinement in large plasmas}

In the large plasina experiments, the princtpat effort was to ascertain the scaling of $t_{E}$ with density and current. Figure 3 shows the variation of the electron temperature proftle with olasma current at fixed line-average 
density. The electron temperature profile broadens substantially with increasing current. The region wthin the $q=1$ surface, as detemined by the inversion of the sawtooth oscillation on the electron cyclotron emisston data, increases with increasing current (as expected) and the temperature proffle is relatively.flat within the $q=1$ surface. In large plasmas, the perfod of the sawteeth varfes from 18 to 36 msec. Quite often, much iarger amplitude sawteeth occur at approxtmately twice the nomal period; this is similar to a phenomenon prevfously observed on D-[II//7/ and Text $/ 8 /$. At larger radt1, a smaller Inverted sawtooth is observed between the longer sawteeth. Figure 2 shows an example of a discharge undergoing a transtition from nomal to approximately double-perfod sawteoth. Sawteeth are also observed on the line denstity, neutron entsston, and loop voltage in thts low-q (2.6) discharge. From the evolution of the electron temperature with time (Fig. 2), it is clear that sawteeth have an important effect on the dynamics of the core of the discharge.

The scaling of the central electron and fon temperatures with density for $I_{p}=1.4 \mathrm{MA}$ is shown in Fig. 4. The electron temperature decreases weakly with increasing density and the difference between the electron and fon temperature decreases with increasing densfty. The siow decrease in central electron temperitiure with increasting density also correlates with a decreasing $z_{\text {eff. }}$

$Z_{\text {eff }}$ can be deduced by three techniques: pulse height analysis of the $x$ ray spectrum, bremsstrahlung measurements in the visible spectrum, and analysts of the plasma resfstivity. The uncertainty in the pulse hefght analysis determination of $Z_{\text {eff }}$ is $\pm 30 \%$ and in the vistble bremsstrahlung determination is $\pm 20 \%$. The value-from the plasma resistivity depends upon the resistivity model. The inclusion of the neoclassical correction for the trapped partfeles makes a dffference of about a factor of 0.5 to 0.65 in the

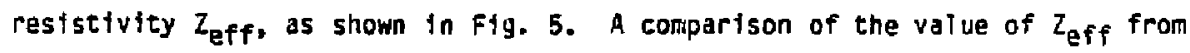
these three techniques versus ifne-averaged denstty and current is shown in

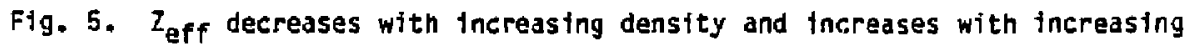
piasma current. Pulse height analysis measurements indicate that the varlation in $Z_{\text {eff }}$ with $\tilde{n}_{e}$ is due in part to changes in the titanium content. In the large plasma confinement studtes, whth are described belaw, values of $n_{T j} / n_{e}$ approach $5 \times 10^{-3}$ at low densities and were found to decrease by a factor of 20 to 100 as the electron density was increased by a factor of 
two. Moreover the satto of $n_{T !} / n_{e}$ increased with increasing current at a fixed density. The trends observed by the $x$-ray pulse height analysis dizgnostic were also observed by spectroscopic measurements in the VUV regton. In comparison with the experiments conducted in June, the valuc of $Z_{\text {eff }}$ is lower. The titaniun in the discharge is belfeved to orfginate from the moveable lfinfter since only small concentrations of iron and nfckel (the matre constituents of the vacuum vessel walls) are observed.

In spite of significant concentrations of titantum at low density, the central radiated power is small compared with the local ohmic heating power. Estimates using coronal-equllfbrium rates $/ 9 /$, as well as more detalled calculations Including transport, using the MIST code $/ 10 /$, Indicate that the maximum power radtated from titanium in the centrat plasma is up to $20 \mathrm{kH} / \mathrm{m}^{3}$, which is small compared with the input power. Bolometer measurements conflim this conciustion. Although the total radtated power is typically $60-90 \%$ of the ohinle input, the radiated-power proftle is very broad and is $\$ 20 \%$ of the Tocal ohmic input on axis. Figure 6 shows a comparison of the raddated power profile and the input profile for the discharge shown in Fig. 1. The charge exchange component of the bolometer power is estimated to be small. The ohmic power was calculated assuning both Spitzer and neoclassical resistivity models. In the Spitzer model, $q$ on axts is calcuilated to be 0.9 til this case. The energy confinement time as a function of density is shown for various currents in Fig. 7. Over the limtted density range studfed, the energy confinement time increased IInearly with density. The confinement time at a given densfty decreases with increasing current $\left(\tau_{E} \propto l_{p}^{-0.8}\right)$. In order to investigate whether the variation in confinement time was due to plasma current or due to changes in the safety factor, a lintted number of $0.8 \mathrm{MA}$ dfscharges were made at $1.8 T(q=3.2)$. Compared with the higher field discharges (at the same current), the confinement time was lower indicating that changes in confinement time were due to changes in $q$ rather than in $I_{p}$ according to the relation

$$
\tau_{E} \text { at } \tilde{n}_{e} q^{0.8}
$$

This result is in agreement with the low density confinement time scaling found on 0-III /11,12/. The possible role of sawteeth and the elevated globat radiation level in the observed $q$ scaling is presently being studied. 
$\cdot \cdot$

Although both the electron temperature proflle and the central ion temperature are well enough known for the purpose of assessting global confinement, the difference between $T_{e}(0)$ and $T_{f}(0)$ is not known welt enough to determine accurately the centrat ion energy confinement, or, equivalently, the multiplier a on neoclassical fon thermal conductivity. Trenus observed in the a required to match the avallable data, however, may be meaningful, In generat, at lower currents $\left(I_{p}<0.8 \mathrm{NA}\right)$ Chang-Hinton //3/ neoclassical transport is adequate to reproduce the measured neutron enission, using the electron cyclotron entssion measurements of the electron temperatures proftle. At higher currents, up to $1.5 \mathrm{MA}$, the central ton energy confinement time from Chang-Hinton neoclasstcal theory. 15 as long as 1.5 seconds. Under these circumstances inultiplters ranging up to $~ 6$ times chang-Hinton transport are required to reproduce the measured $\left(T_{e}-T_{i}\right)$. In these cases, however, $\tau_{E j}(a / 2)$ stfll exceeds $\tau_{\mathrm{Ee}}(\mathrm{a} / 2)$ by actor of $\sim 2.5$. In the high current (low-q) discharges, strong sawteeth are observed 0.1 the neutron emission, and the neoclassical ion energy confinement time exceeds the sawtooth repetition time by a factor of $\gtrsim 20$. Thus, it appears reascnable that sawtooth-induced ion energy transpert could affect $T_{e}(0)-T_{i}(0)$. Prelfimfnary calculations using a sawtooth mixing model in the BALQUR /14/ simulation code indicate that sawtooth mixing of the fon temperature increases the time-averaged value of $T_{e}(0)-T_{i}(0)$ by $250 \mathrm{eV}$, compared to a model with purely neoclassicat fons and sawtoothing electrons.

\section{Stze scaling experiments}

In order to examine confinenent scaling with minor radius in TFTR, a number of experiments were performed at reduced aperture, using the noveable lfmiter. In the minor radius scaling experiments, $q$ was maintained in the range 2.7-3.5 and the minor radius varted from 0.41 to $0.83 \mathrm{~m}$. Discharges with a minor radius of $0.41 \mathrm{~m}$ were very difficult to control, In part due to the relatively low gas feed rates requtred compared with the design of the gas injection valves. Although some discharges appeared marginally acceptable, the following discussion will omit the $0.41 \mathrm{~m}$ plasnias since the analysis to date has shown the data to be internally inconsistent, probably associated with the determination of the plasma position in these low current discharges. The scaling of the energy confinement time with density for different 
minor radif is shown in FIg. 8. The data shown in Figs. 8 and 9 fnclude data from the June ' 83 run with $0.69 \mathrm{~m}$ discharges. There is a relatively weak dependence of $\tau_{E}$ on minor radtus as the winor radius was varted from 0.55 it to 0.83 m. Qutte clearly the scaing of $T E$ is not consistent with INTOR scaling. The confinemert time in TFTR exceeds the confinement time predicted by INTOR scaling by a jactor of $2-5$.

The combination of a weat rinor radfus scalfing and relatively good confinement time compared with orevious smaller machines with a minor radfus of 0.4 $\mathrm{m}$ such as PLT /15/, POX /16/, ASDEX /17/, and D-1II /11,12/ Implies a strong mafor radius scaling stmitar to that which has previously been discussed by Leonov et al. $118 /$, Pfetfer and Waltz $/ 19 /$, and Blackwell et al. $/ 20 \%$. For comparison, the TFTR data are plotted versus $\pi_{e} R^{2} \& q^{0.8} \frac{1}{\text { in }}$ Fig. 9. This is a modified form of the scaling proposed recently by the Alcator group $/ 20 /$ to incorporate the $q$ scaling observed on TFTR and $0-I 1 I$ $111,12 \%$. The data fro- PLT with $q$ in the range from 3.5 to 5 are shown for compartson to obtain a sense of the $R$ sealing. For a stmilar aspect ratio of \% 3.3 the data from PLT extrapolate to TFTR relatively well fndicating (length) ${ }^{3}$ scaling; however, the higher aspect ratio $0.55 \mathrm{~m}$ discharges indicate that the scaling wfth a may be weaker and the scaling with $R$ correspondingly stronger. These results conftm the favo.able scailing of confinement time with size; however, much more analysts of the TFTR data is required to establish the detalled scaling with both major and minor radís.

\section{COMPRESSION EXPERIMENTS}

In compresston experiments, a small plasma (typlcally $a \simeq 0.55-0.60 \mathrm{~m}$ ) is established at a large major radius $(R=2.95-3.05 \mathrm{~m})$ on the moveable 1imiter. It is then compressed rapldly in major racius by programming a step decrease in the reference posttion and simultaneously discharging capactior banks in the equilibrium fleld system to asstst the rectifier power supplies. In a full compresston, the glasina is brought to rest in contact with the bellows cover plates and maintained for $Z 1$ sec at the final postition $(R=2.07-2.17 \mathrm{~m}, a=0.45-0.55 \mathrm{~m})$. We have also perforined partial compression (free-expansion) experiments, in which the plasma is moved part way across the vessel and then allowed to expand until th again contacts the material limiters. 
Comparison of the reai-time magnetic measurement of the plasma position with the preprogrammed reference indicates that the position reedback loop is controliling the measured position to within $\sim 10 \mathrm{~mm}$ of the final postcompressio: reference value in $\leq 20 \mathrm{~ms}$ after the start of compression, as long as sufficient energy is provided by the compression capacitor banks. However, determinations of the plasma posttion fran electron cyclotron emission temperature measurements show that the piasma is not compressed as rapidiy as the real-time magnetic position measurement indicates, instead taking $\sim 40 \mathrm{~ms}$ to reach the finat position. This discrepancy is due to the effects of eddy currents induced by the plasma motion and current increase (for which the real-time magnetics posttion is not at present corrected) and by the equilibritu field (for which the corrections employed are not optimized). Subsequent analysis of the magnetics data fncluding eddy current effects has shown agraement (within $50 \mathrm{~mm}$ ) between the deduced position and the position of the electron temperature. In future experiments, improved eddy current corrections will be incorporated in the real-time measurement used in the position fedback control, and the compresston time should be significantly reduced.

Figure 10 shows the evolution of a typtcal compresston discharge, for which the compression ratio in major radius was $C=1.38$ and the 1 imiter $q$ about 2.6 before and after compression. In such discharges, the plasma current increases in accordance with the adiabatic scaling $l$ aw $\left(I_{p} a C\right)$, al though the interpretation of this result also depends on a detailed analysis of eddy current effects (which remalns to be performed), to determine the magnitude of plasma skin currents induced during compression. on the other hand, the line density scales less strongly than prodicted. The reason for this is not quantftatively understood; however, qualitative model is suggested. Coing compression, the piasma edge expands at the rate of $\sim 7$ $\mathrm{mm} / \mathrm{ms}$. This was determined by conducting a series of partial compression (free-expansion) experiments and observing the time at which the plasma edge reached the bellows cover plates, as indicated by an abrupt fncrease in the boloneter signal and the appearance of light on the plasma TV system. Thus when the plasma is "fully" compressed, the expanded edge of the plasna is scraped off on the beliows cover plates and some particles may be lost. Support for this model cones from the observation that during the initial $3 / 4$ of the compresston stroke, the line density scales approximately as 
predicted from the electron eyclotrori entssion major radius deterination. Only at the end of the stroke when the plasma comes in contact with the wall does the deviation occur.

For the conditions of Fig. 10, the variation of the fon and electron temperature around the compression \pm 1 me is shown in Fig..11. The fon temperatures as determined from neutron emission and Doppler broadenting of the $T_{f} X X I K_{a}$ line are in good agreement, although the time resolution of the latter data is not adequate to follow the temperature rise during compresston. The neutron ion temperature increases approximately as $c^{4 / 3}$ as predicted by the ideal scaling law. The electron temperature increase, however, is consistently less than predicted by the fded scaling law. A simtiar discrepancy in the electron temperature scalting was observed on ATC and was attributed to the fact that the compression time was not negligible in comparison with energy confinement time /21/. Zero-dinensional code simulations findicate that wfth a compression time of 40 ms, the enerigy loss through the electron channel accounts for the observed electron temperature rise.

\section{CONCLUSIONS}

The recent experiments enabled us to expand the operating range of TFTR and to document a wider range of plasma conditions. The more extensive scaling studies of the energy confinement time conftem inftial results that $\tau_{E}$ fncreases with size and with densfty. Confinement tines in excess of 0.255 were achieved.

Initial compression experiments have shown that the feedback systems are abie to control the plasma successfully during compresston. The increase in the electron and ion temperatures is in reasonable agreement with expectations for a $\sim 40$ ms compression time. The results of the recent experiments have demonstrated successful plasma and machine operation in preparation for the forthcoming neutral beam phase.

\section{ACKNOWLEOGMENTS}

A project the size and complexity of TFTR requires the support of a large and very dedicated staff. It is a pleasure to acknowledge the very many 
engineers, computer programers, and technictans who have enabled us to conduct these experiments. We are grateful to H. P. Furth, P. Rutherford, and J. R. Thompson for their cantinued leadershtp and support. This work was supported by US Department of Energy Contract No. OE-ACO2-76-CH0-3073.

\section{DISCLAMIER}

Thin report was prepared as an ecoount of work eponioned by an syecy of the Uniled State Gumernment. Neither the United Stata Governmeat mor any asecey thereof, nor any of their

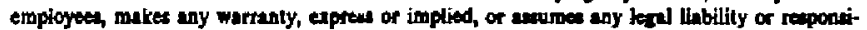
bility for the scouracy, completencen, or unciuleces of any infonantion, sppurates, prodect, or process diselosed, of represents that its ue would oot infringe privately owned riphts. Reforence bercin to any apecific commercial product, procesen, of cervice by tredo anme. trademark, manuincturer, or atherwise does not neceanrily conatiute or imply its endonement, recom-

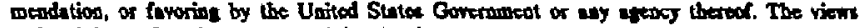

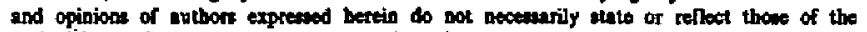
United Stste Gomernment or any agency thereof. 
REFERENCES

apermanent address Dak RIdge National Laboratory, P.O, Box Y, Dak Ridge, TN 37830

On leave from RCA David Sarnoff Research Center, Princeton, New Jersey

COn leave from Idaho National Engineerfing Laboratory, EGsG, Idaho, Inc.

11/ YOUNG, K. M. et al., Plasma Phystes, 26 (1984) 11.

12/ EFTHIMLON, P.C.et al., to be published in Phy5. Rev. Lett.

13/ DYLLA, H. F. et al., Proc. 30th Nattonal Symposium of the American vacuum Soc Fety, Boston, ibvenber 1983, J. Vac. Sci. Technol. (in press).

14/ OYLLA, H. F. et al., Proc. 6th Intern. Conf. on Plasma-Surface Interact ons, Nagoya, Japan, May 1984, and J. Mucl. Materlals (to be pubi is shed).

15/. MURAKAMI, M., CALLEN, J.D., and BERRY, L. A., Kuct. Fuston, 16 (1976) 347 .

16/ HAMRYLUX, R. $\dot{v}$. et al., Proce of the course in Physies Close to Thermonuclear conditions, (Varenna, Italy) Report EUR-FU$8 R \mathrm{R} / \mathrm{XII/476/80.}$

I7) PFEIFFER, W. et al., GA Technologies Repert, GA.Al6994 (1983).

18/ SNIPES, j. et al. Bull. An. Phys. SOC., 28 (1983) 1034.

19/ POST, D. E.. et al., At. Data Nucl. Data Tables, 20 (1977) 397.

l10/ HULSE, R., NucT Tecnnol./Fusion, 3 (1983) 259.

III EJIMA, S., et al... Mucl. Fuston, 22 (1982) 1627.

II2l Magami, M., et ai., Muci. Fusion, 22 (1982) 409.

113/ CHANG, C. S., and HINTON, F. L., Phys. Flutds, 25 (1982) 1493.

$114 /$ SIKGER, C., Prinçeton Plasma shysics Laboratory Report Ho. PPPL-2073 (1984).

115/ HAWRYLUK, R.J., et al., Nucl. Fuston, 10 (1979) 1307.

116/ KAYE, S. M., et a. Princeton Plasma Fhysics Labozatory Report No. PPPL-2109

117 KLÜBER, O.. and RURPAN, H., Max-Planek Institut für Plasmaphysik, IPP II $/ 72$ (1982).

118/ LEONOV, $V_{0} M_{n}$, et al., in Plasma Physics and Controlied Nuclear Fusion IAEA, VIenna, 1981 , Vol. I, p 393.

129/ PFEIFFER, W. and WALTZ, R. E., Nucl. Fusion, 29 (1979) 51.

120/ BLACKHELL, B., et a ., in Plasma Physics and Controlied Nuclear Fusion Research, IAEA, Tienna, IAEA-CN-41/1-3 (1982).

/21/ BOL, K. et ai., Phys, Rev. Lett., 29 (1972) 1495. 
FIGURE CAPTIONS

FIG. 2 Evolution of plasma current, loop voltage, major radius, $\beta_{\theta}+z_{1} / 2$, and line density during a large p?asma discharge.

FIG. 2 Central electron tenperature measurenents from the electron cyclotron emission compared with those from pulse height analysis of the $x$-ray spectrum for the discharge in Fig. 1 . Corresponding central ion temperature measureants fron neutron entssion compared with those from Doppler broadening of TixXI Ko lines.

FIG. 3 Variation of the electron temperature profile with plasma current at $\pi_{e}=2.3 \times 10^{19} \mathrm{~m}^{-3}$ for $I_{p}=1.0,1.2$, and $1.4 \mathrm{MA}$ and $\hbar_{e}=2.1 \times$ $10^{19} \mathrm{~m}^{-3}$ for $\mathrm{I}_{\mathrm{p}}=0.8 \mathrm{MA}$. $\mathrm{B}_{\mathrm{T}}=2.7 \mathrm{~T}$.

FIG. 4 Variation of the central electron and ion temperature with density. $B_{T}=2.7 \mathrm{~T}$.

FIG. 5 Variation of $Z_{\text {eff }}$ with density and current as determined by pulse height analysis of the $x$-ray spectrum, bremsstrahlung measurements in the visible and analysis of the plasma resistivity. ${ }^{B_{T}}=2.7 \mathrm{~T}$, $a=0.83 \mathrm{~m}$, and $\mathrm{R}=2.55 \mathrm{~m}$.

FIG. 6 Comparison of the radiated power proftle with the ohmic heating profile for the discharge shown in Fig. 1 .

FIG. 7 Energy confinement time as a function of density in the large plasma $(a=0.83 \mathrm{~m}$ and $R=2.55 \mathrm{~m}$ ).

FIG. 8 Scaling of the energy conffnement time with density for different minor radius discharges. $B_{\Gamma}=2.7 T$ and $2.7<q<3.5$.

FIG. 9 Scaling of $\tau_{\varepsilon}$ with $\tilde{n}_{e} \cdot R^{2}$ a $q^{0.8}$ using the data from both the large plasma experiments as welt as the size scaling experiments. The data from PLT and PDX are shown for comparison. 
FIG. 10 Evolution of the plasma current, line density, and major radius in a compresston discharge. The major radius plot is based on the realtime magnetfc measurement of plasma position. During a discharge, these parameters are feedback-controlled to match preprogramed references, except that the plasma current and density feedback loops are dfsabled for a short tine around compression so that the effect of compression can be evaluated straightforwardiy.

F16. 11 Temperature measurements on a fast tfme scale around compression, for the condttions of Fig. 10. Central electron temperature is from $x$-ray pulse-helght spectrum. Central ion temperatures are from neutron enission and Doppler broadening of $T_{j} x x t K_{a}$ radiation. 


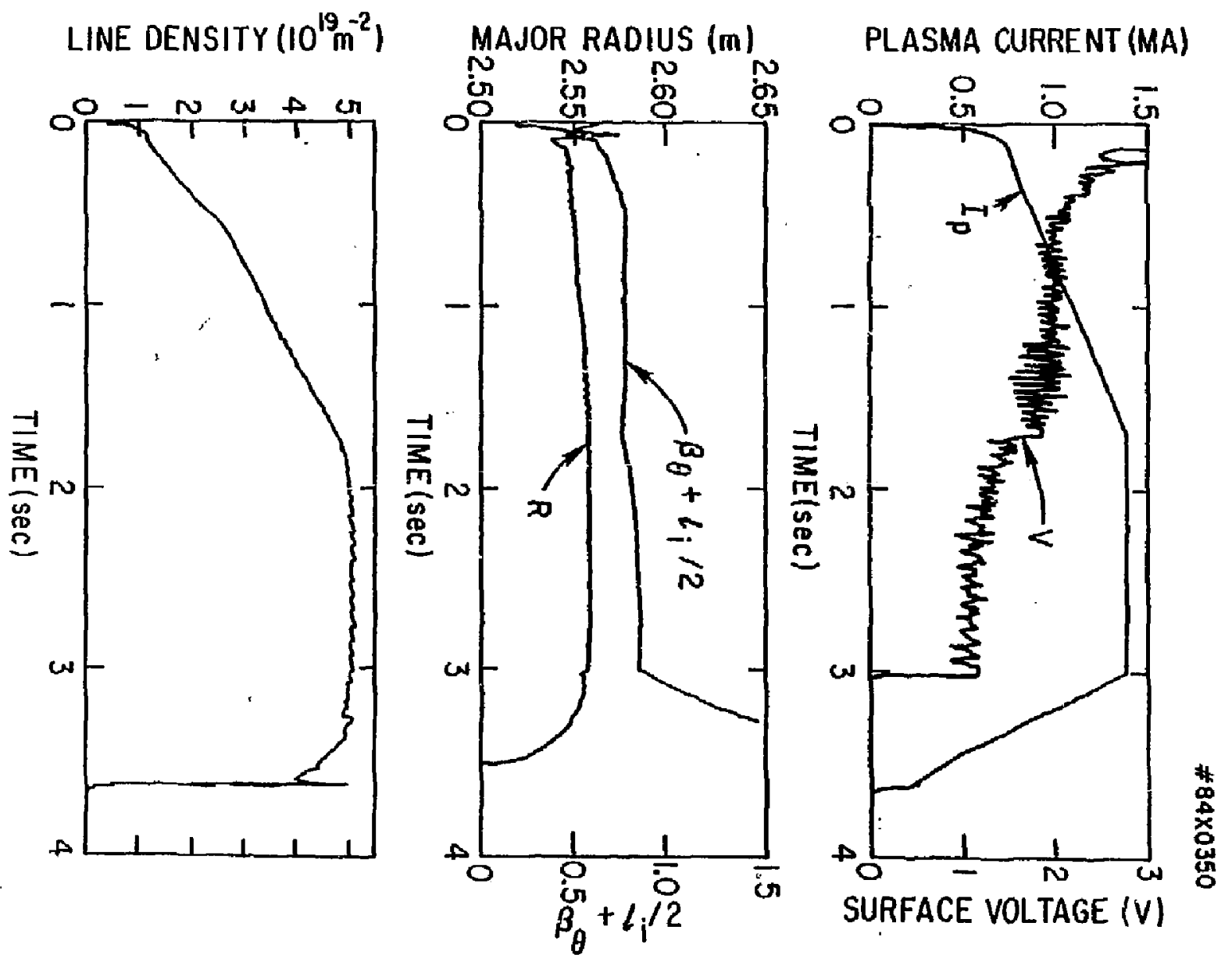




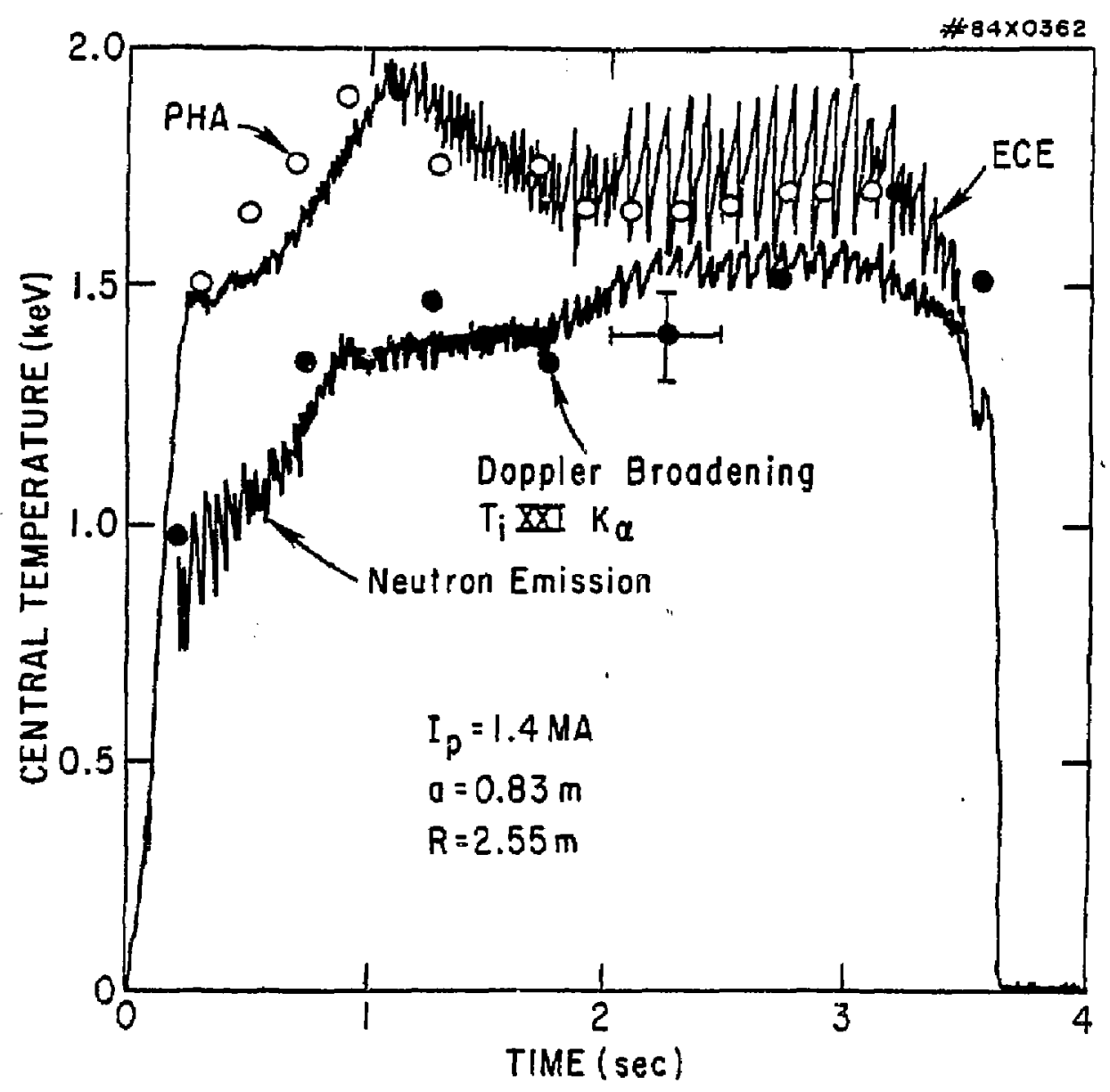

EIS, 2 


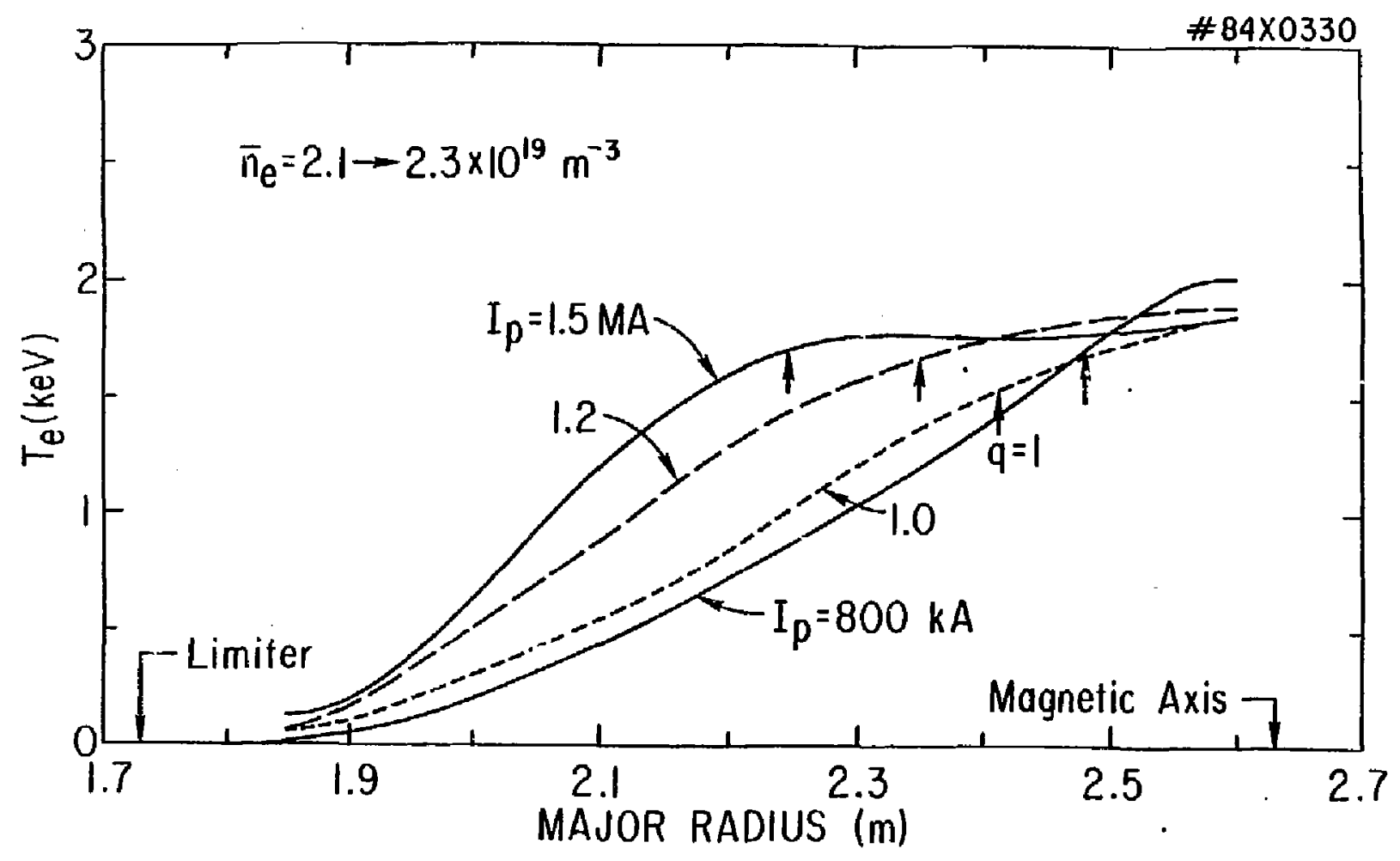




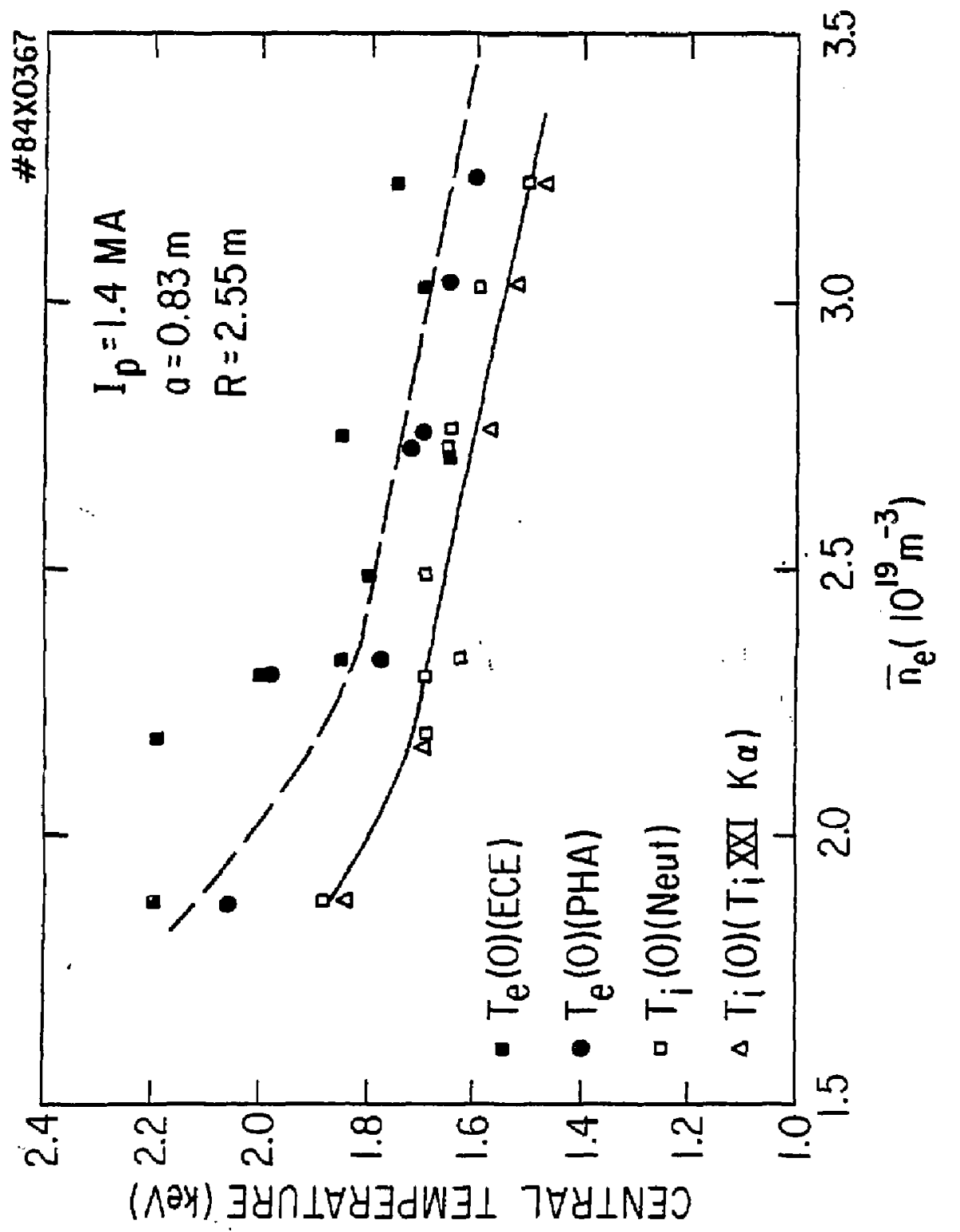





Fig. 5 


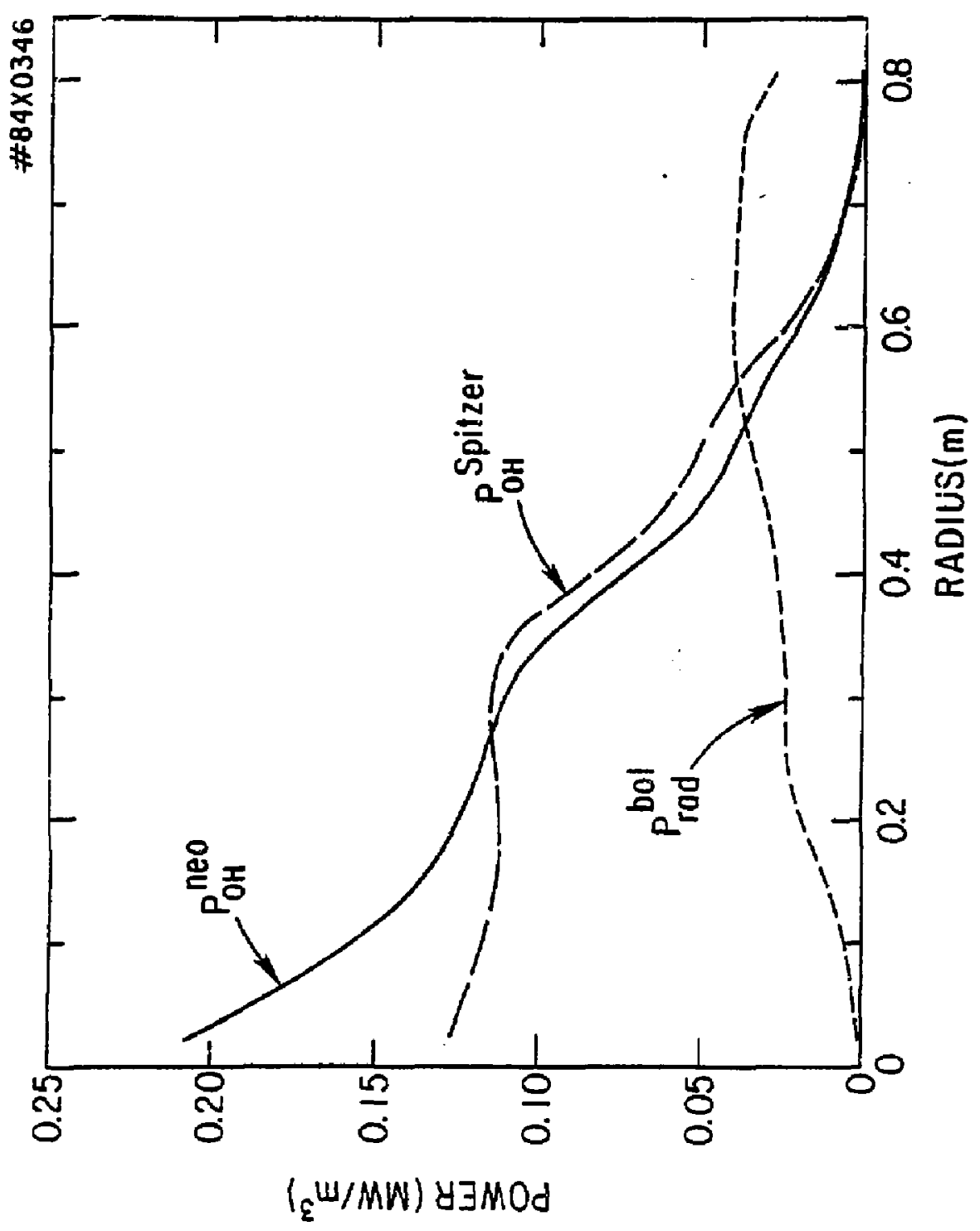

它 


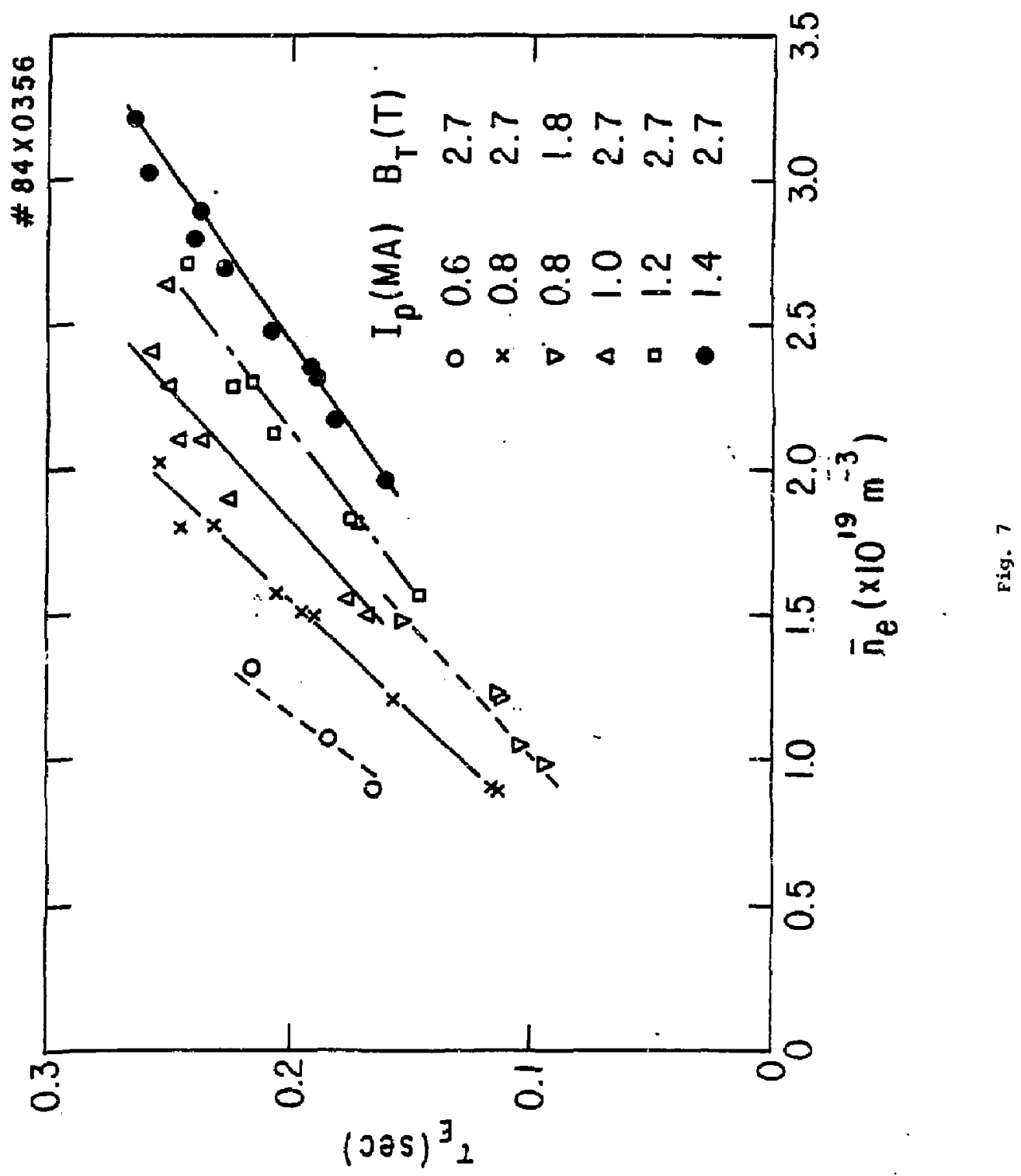




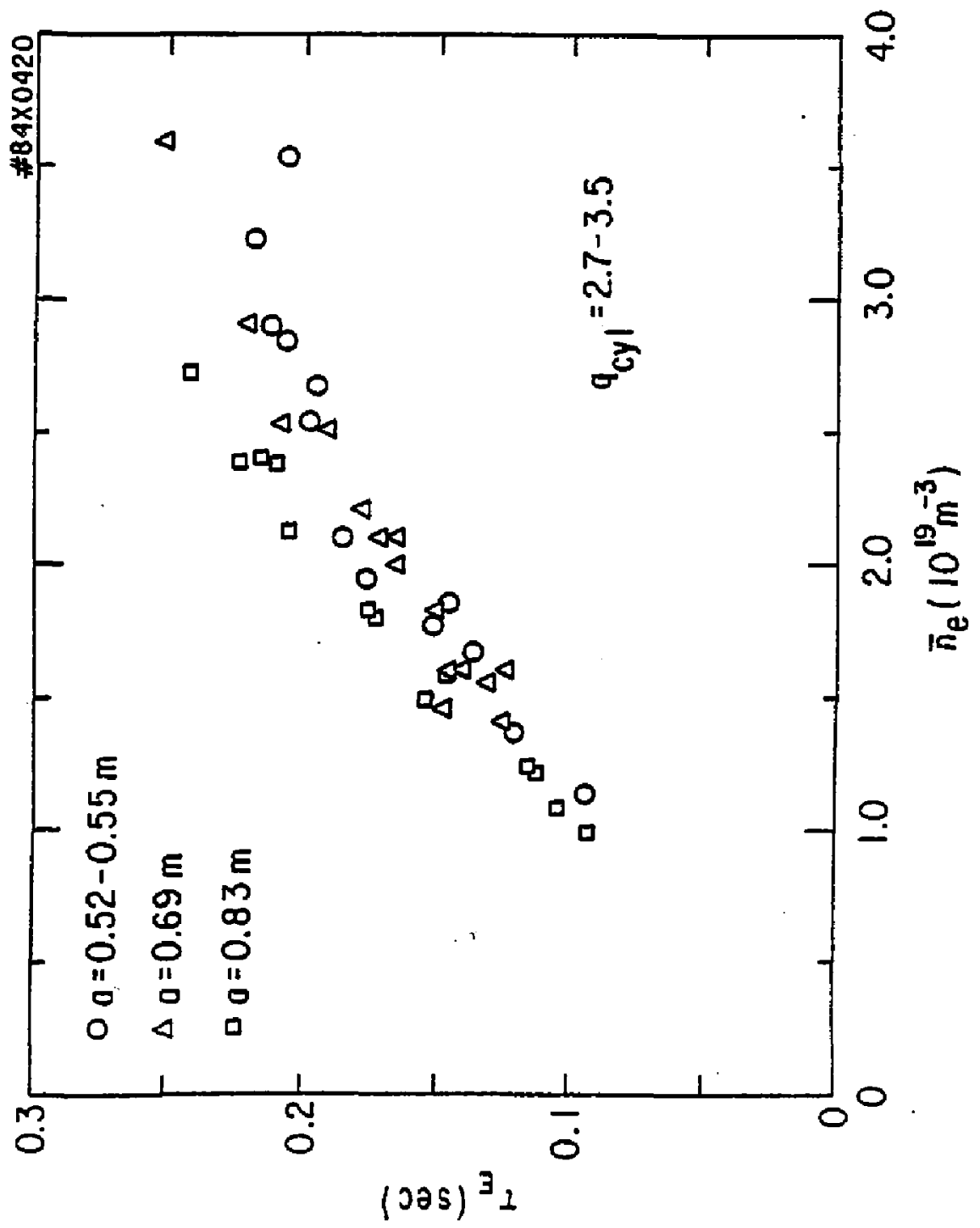




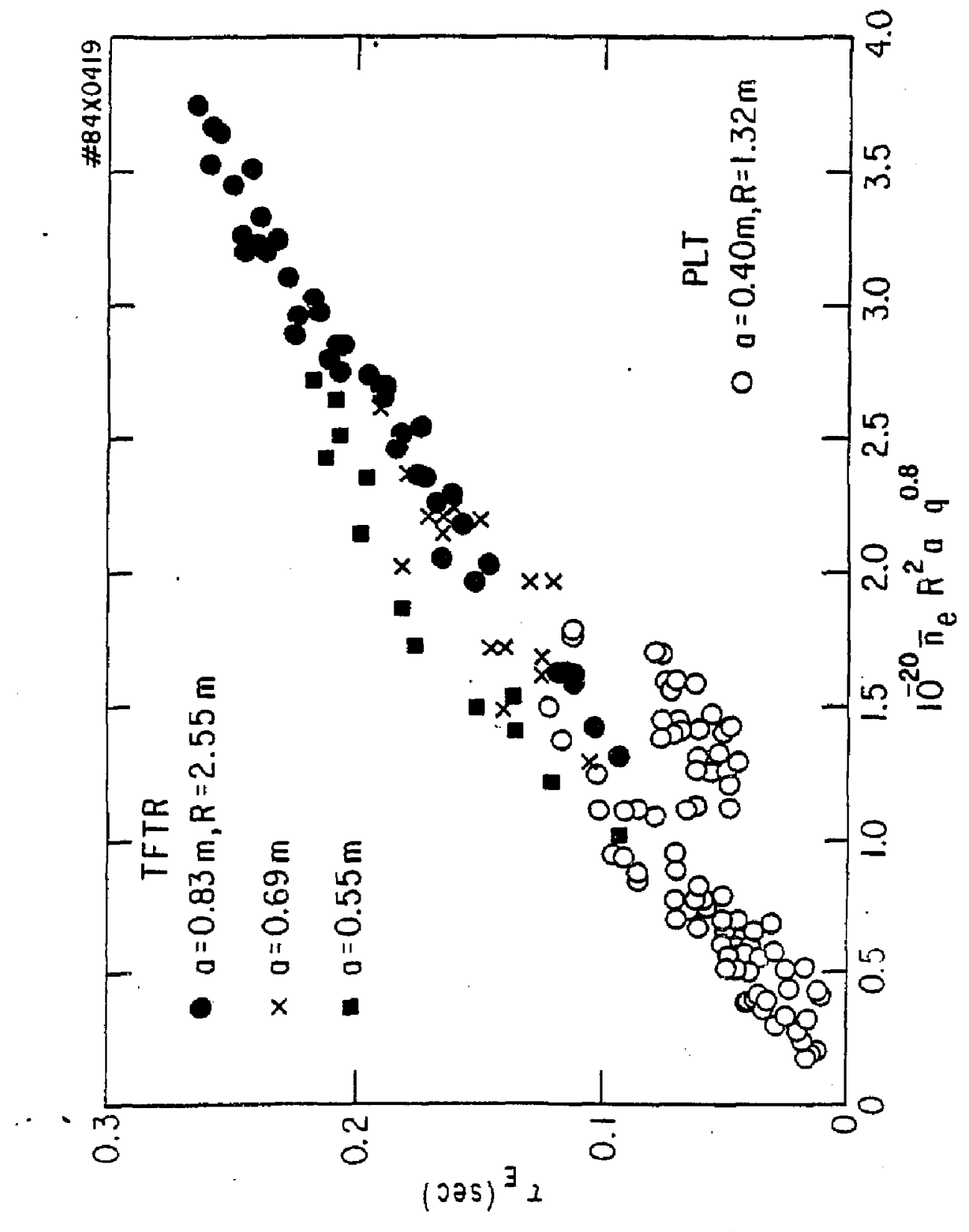

on 


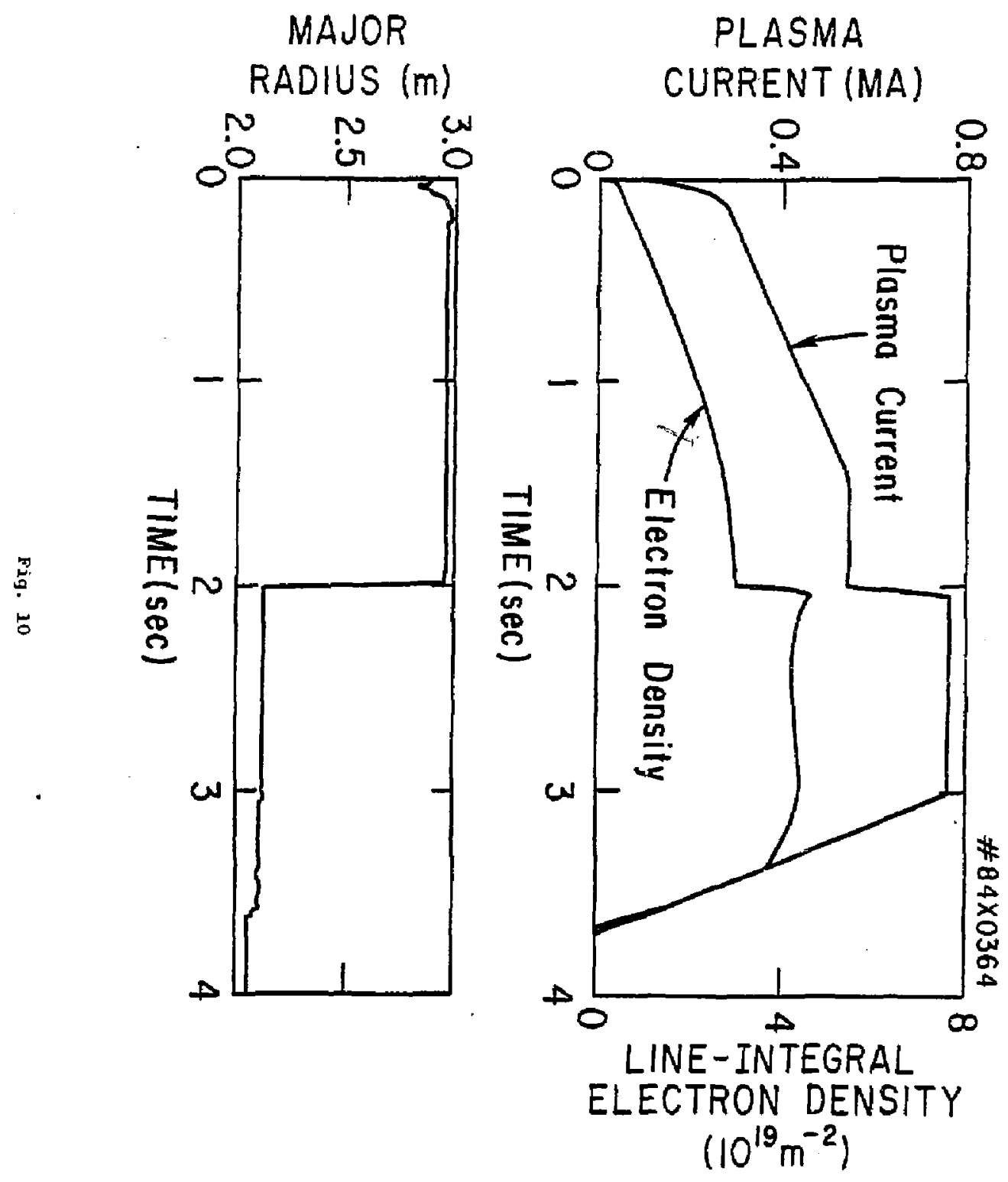




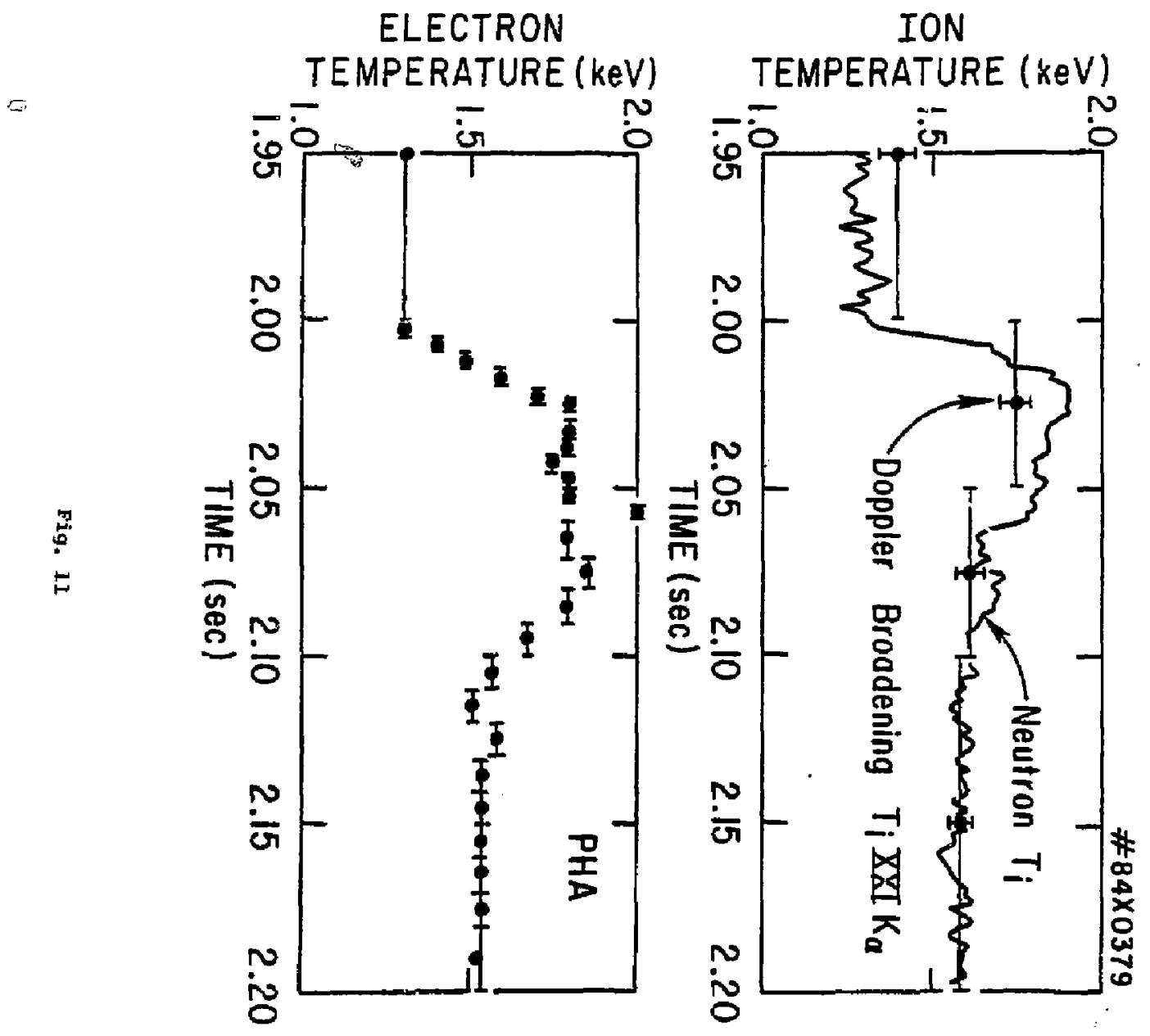




\section{EXTIERAL OISTRIBUTION IN NDOITION IO TIC UC-20.}

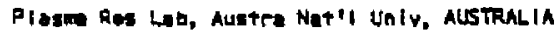
Dr. Frenk J. Poolonl, Unly of wollongong, Austruh, ih Prot, J,R, Jones, flindars UnlY., AUSTRALIA Prot. MH. Bronnen, UnIV 5ydrin, AlSTRublA Prot. F. Con, Inst theo Phys, ALSTRIA Frot. Frenk Verheetit, Inst theoret lsche, BELGIu Dr. D. Palubo, Og Xil fusion Prog, belolu Eeole Royele Mllitaira, LAb do Pnys Plaseas, Belgilu Dr. P.H. Sekanake, Un iv Estadua I, ERAZIL

Dr. ER, Jases, Unjy of Aiberra, CNHDA

Prot. J. Tehenmenn, Univ of Montrese I, CAMkDA.

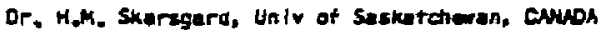

Prot. S.R. Srwenlyosan, Universlty of Calgary, Cawas

Prof. Tudor w. Joinston, :KR-Energite, Cewach

Or. Hannes garmard, Univ Artitlsh Columble, chuph

Dr. Mo. Bechrnakl, me Technologiew, ince. CNwon

Znongu LI, Sw Inst Phystes, oulm

Library, Teling the University, CHIM

bibrorlan, Instifute of Physics, OHIMA

Inst Plese Phys, Aeadmie Sinles, OHIM

Dr. Potor Lukac, Konenskaho Unly, CzEchosLoYAKIA

The Li brarlan, Culha Luberatory, ENGLANo

Prof. Schatzman, Observatolr do Nise, FRAMCE

J. Redet, Centape, FRAuEE

AM Dupes Library, AH Dupas Library, FRANEE

Or. Toe Mul. Acedeny BIbliogrephle, Hokg Kow

Proprint Library, Eent Res Inst Phys, HUNGary

Dr. S.K. Trehan, Panjab Universlty, INOIA

Or. Indre, Hohen Lal Ods, Benaras Hindu Univ, INOIA

Dr. L.K. Chavdh, South Gujarat Univ, I HDIA

Dr. R.K. Chnajlant, Var Ruenl Marg, Inoia

P. Kow, Physieat Researeh Lab, InDIA

Dr. PhlIIIp Rosenau, Isreel Inst Tech, ISRAEL

Prot. S. Cuporman, Tot Aviv Univerality, ISRAEL

Prot. G, Rostegn 1, Un IY DI Fodove, ITALY

Llorarlan, Intil Crr Theo Phya, ITALY

Miss Cielle Oe Palo, Aasoc Elahtoh-Gaten, ITAkY

giblioteca, dol CNR ERATOM, ITALY

Or. H. Yamato, Tothlka Res \& Der, JAPAk

Prof. M. Yosnlkewe, JAERI, Tokei Ras Est, MPAK

Prof. T. Uen lde, uniweslty of Tokyo, IAPAN

Rasearch Into Conter, Magoya University, JAPAN

Prot. KyoJi N1sinikgwa, Univ of Hirosnima, JAPAN

Prof. SIgoru Mori, AAERI, ARAN

LISTory. Kyoto Unluers iTy, JAPAN

Frot. Ienlro Xawakanl, Nihon Un lv, MPAN

Frot. Setoshi Itah, Kyushu Unlwarslty, JAPAN

Toeh Inte Dlulislen, Korae Atonic Enorgy. KOREA

DF.. R. Englanc, Cludad Universitaria, MEXICO

El bliothoek, Fertinst Yoor Plase, NETHERLANos

Prof. 8.5. LIlor, Univarslty of Walkata, NEW IEA AND

Dr. Surash C. Shama, Univ of Gaiabor, NIGeRiA
Prot. d.A.C. Cobrel, Inst Superlor Toch, PORTuCAL

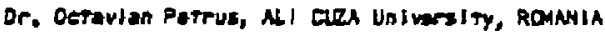
Prof. MaA. Hell iberg, University of Rjitel, 50 AFRICA Dr. Jowan de Villilers, Atcolle Enorgr Bd, SO AFRICA Fuslon Q1Y. LIbrery, JEN, SPAIN

Prot. Hans Witheleton. Chel mars Unir Teeh, SIEDEH Dr. Lonsart Stenfla, Univarsity of LMEA, SWEDEN Llbrary, Royal Inst Toeh, SwEDeN

Dr. ErIk T. Karisen, Uppesele Univarslter, SHEDEN Centre de Recherchesen, Ecola Poivtech Fed, SwITZRRLANi Or. W.L. Welse, Mat'। Bur Stand, ISSA

Dr. H,M, Stued, Georg Inst Teen, USA

Dr. S.T. Wu, Unlv Alubere, USA

Prot. Normen b. Olesen. Unty 5 Floride, USA

Dr. Banjealn Ma, lewe Stato Unlv, USA

Prot. Magne Kelstlansen, Twes Teen Unlv, uSA

Dr. Raymond Asken, Auburn Un Iv, USA

Dr. V.T. Tolok, Kharkor PnYe Teen Ins, USSR

Dr. D.D. Ryutoy, Sibarian Aead SEl, USSR

Dr. 6.A. EIlacev, Kurehatov InstIture, USSR

Dr. Y.A, Glukhlkh, Intt tectro-Phyaleal, USSR Inseltute Gen. Physites, US5R

Prot. T.d. Boyd, Univ Colligg N Wa les, whes

Dr. K. Sehindier. Poune Unt varettat, W. Gefounvy Wuclear Ras Estab, dut th LTd, W. GERANYY Liararlen, Moxplanck Institut, W. Gepawy Dr. H.J. Kacpplar, University Stuttgart, W. GefanAYY Bibllothak, Inst Plasedorgehung, W, Gereant 